\title{
Comparison of Branding Strategies of Pharmaceuticals \& Fast-Moving Consumer Goods: An Analysis of Modern World Need
}

\author{
Tariq Mehmood Dar and Neelofer Tariq
}

\begin{abstract}
Branding is an integral part of any product or service. Branding gives identity to a product, whether it is tangible or intangible. Branding tactics and strategies are not new in the marketing of fast-moving consumer goods (FMCGs), whereas, in the pharmaceuticals (prescription medicines), it is challenging. This article aims to analyze the branding strategies currently in use or been used in the pharmaceutical industry globally; however, this analysis is accomplished with a comparison of the fast-moving consumer goods industry. Thirty-four peer-reviewed studies from around the world in the tenure of 2010 till date have been utilized to analyze the following research. Fore mostly, the branding strategies used in the respective industries have been reviewed for this research's objectivity. The end deductive results obtained from the comparison are employed to conclude how these findings can fulfill the modern world needs.
\end{abstract}

Index Terms - Branding strategies, FMCGs, prescription medicines, tangible/intangible products.

\section{INTRODUCTION}

\section{A. Existence of Medicines}

Medicines, pharmacies, or medicinal drugs are proficiently the different terms relating to the same meaning of curing and treat patients suffering from different diseases. With humankind being evolved to updated ways of living and every aspect of human life be changed accordingly as per its environment; Medicine became a vital part of human life. The human body is made to fight bacteria and viruses to some extent, and at the same time, to have the human body's maximum capabilities, the human immune system shows the dire need of medicines. Since life's existence on earth, discoveries of medicines have been existed \& time-tested; safe-to-say updated as well. Doctors updated to physicians, physicians became specialists, but the essential element needed to cure an ill patient is a medicine with perfect diagnosis. Though the health practitioner's professional qualities matter a lot and cannot be praised enough, medicines work hand-in-hand in the appropriate treatment of a patient.

Medicinal discoveries have been challenged around the world, in every century under strict circumstances. Globally, researchers debate upon the benefits of allopathic, herbal,

Published on November 26, 2020.

Dr. Tariq Mehmood Dar, Director Marketing \& Sales, Pharmaceuticals, UAE/Pakistan.

(corresponding e-mail: drtariqdar@ gmail.com)

Ms. Neelofer Tariq, Professional Sales \& Marketing Trainer, UAE/Pakistan.

(corresponding e-mail: neelofer.hanif@gmail.com)
Ayurvedic or homeopathic medicines etc. Almost all natures of medicines carry profound characteristics and perform accordingly on the patient's body. However, these agendas describe how ample prominence medicines hold in the world from its existence till its ending. Introduction of medicines by researchers to cure any kind of disease, condition, or syndrome makes up a giant corporate sector known as the "Pharmaceutical Industry."

\section{B. The Pharmaceutical Industry}

The pharmaceutical industry itself deals with the discovery of medicinal drugs, which aids in the treatment of patients. Along with the very purpose of discovering medicines, respective industry covenants with the selling of medicinal drugs. This, however, makes the pharmaceutical industry one of the sensitive industries of all times in history. Concrete time-tracked shreds of evidence exist that narrates the pharmaceutical industry's environment in its past and present, which shall aid in predicting the future of the industry through the end of this proposal.

\section{History of the pharmaceutical industry}

The most significant industries of all time, pharma, has not been the same till its existence. It dates back to the mid1800 s to $1945-$ since the pharmaceutical industry has existed. The industry has updated, succeeded, and outperform itself many times. Globally, the industry differs from insight; the work procedures might collide, but rules \& regulations within a specific nation differ. Medicines that easily can be purchased from chemist over-the-counter (OTC) in a country might be legal but is considered stickily abided in another country.

Though the pharmaceutical industry's history was not of the situation mentioned above, and ways of working were relatively more uncomplicated. The variant history of the Pharmaceutical Industry exclusively provides pieces of evidence of being more accessible as governmental policies, rules \& regarding the industry's operation were not adequate and not even announced; in the first place. It defines the lack of national government \& concerned department's attention towards the pharmaceutical industry globally. However, the present pharmaceutical industry's environment differs a lot in numerous manners all over the globe.

\section{The pharmaceutical industry in present world}

The pharmaceutical industry's current environment is a bit dynamic in many ways as the stakeholders show severe fluctuations, which eventually affect the pharmaceutical industry's market condition all over the globe. The industry from the last ten years has been growing substantially from 
the growth rate of $7 \%$ as a whole, including the health care sector (Healthcare equipment' \& healthcare services). As reported by Pharma letter [1], the Pharmaceutical industry was worth to be of 1.3 Trillion Dollars in 2019 worldwide. This statistic strongly evident the dilemma about the intensity of sensitivity, profitability \& market share of the pharmaceutical industry.

Marketers worldwide strive to study behind this much infamous behavior of the pharmaceutical industry and target "the modern world needs" to be the sole reason behind it. The pharmaceutical industry's Past \& present environment is updated \& differentiated in many manners, and branding is top of them. In the past era, branding was only conceptualized \& practiced to the tangible products providing industries such as fast-moving consumer goods (FMCG), automobiles, apparel, etc. However, the present pharmaceutical industry is near entering branding \& marketing strategies' technicalities, primarily making the respective industry a giant market leader worldwide.

Branding \& marketing techniques further diverge and moderately spreads in the pharmaceutical industry in numerous ways as the respective industry does not typically follow traditional branding methods. Researchers debate, globally, around the fact that electronic media is not found to be as successful \& effective in the pharmaceutical industry as in FMCGs.

Therefore, to measure the pharmaceutical industry's progress in branding strategies adaptability over the years, the same industry's branding strategies will be compared to the much anticipated, over-hyped, profitable, and giant industry of FMCGs. FMCGs industry is known for its marketing techniques as it deals with tangible and intangible products; eventually, branding strategies adaptability exists in the FMCGs industry more than any industry. Thus, the intended comparison will help researchers provide a new direction \& a much-demanded dimension to study in. Furthermore, before moving on to dissecting data regarding the objective, it is equally vital to notice the objective above's existing information.

\section{Importance of Branding in the Pharmaceuticals \& FMCG Industry}

Zahra [2] conducted extensive research on comparing the pharmaceuticals \& FMCGs branding strategy, but the study was primarily more focused on the importance of branding for the former industry. The researcher presented a proposal that the pharmaceutical industry has adopted branding strategies much later than the FMCGs industry. Most of the pharma sector investment goes into the R\&D of medicines, which leaves the industry lacking in efficiency marketed in many ways. Thus, through recommendations of giving adhered demanding attention by the pharmaceutical industry, marketers must put equal efforts in selling and marketing of medicines as FMCGs do. Reasons for the given statement majorly defines the fact that pharmaceutical industry is not as same in market share as it was in the past; more medicinal drugs manufacturing firms are entering into the market, which is inviting competition to the industry. Therefore, to cater excess competition, drowning marketing captivity, and maintaining a competitive advantage with the same consistency, pharmaceutical companies \& industry needs to develop effective branding means for itself.

Conversely, the FMCGs industry is an old follower of useful and smart branding strategies as the industry is majorly challenged by competition since its existence. Globally, it is recorded to notice FMCGs companies' investments on their marketing budgets with almost onethird of their earnings. This, however, triggers the prevalent practices of marketing \& branding strategies in the FMCGs industry worldwide.

\section{WHAT IS BRANDING?}

The broad term of "branding" is often misunderstood and mixed with the alienated term of "marketing". Both terminologies are utterly different in each other's working manual; however, the terms mentioned above work consecutively to make a company successful. Before diving into the mystery behind what branding is, on the first hand, it is vital to understand what a brand is. A brand is a name, logo, tagline, design, packaging, and every other constituent that distinguishes an individual brand from another. It is ultimately the specific component of a company that is not similar to any other company.

Likewise, branding \& marketing concepts are confused; brand \& company terminologies are also wrongly assumed. The following example will surely clear out the misconception regarding the prevailed confusion of both the terms: Dove is a brand of Unilever. This makes Unilever the company/enterprise/business that owns a brand called Dove.

Moving onto the branding part of the context, a brand is a significant value that the only one has. Not any brand can copy that from another without permission.

Branding is the process that creates the distinguishing elements of a brand. The cycle ultimately results in forming separate \& particular parts of a product like its name, logo, packaging, symbol, color scheme, and every part, which makes it separable from other brands' products.

Marketers spend massive amounts on R\&D and capitals to find the perfect match of elements to create their brand a unique \& standout benchmark, leading to marketing.

Marketing is the aiding tool that helps companies to create a unique branding strategy for their respective brand. Marketing usually delivers the Brand's message to its potential customers and make them aware of the brand's next move. The accompanying act of marketing makes it a whole long, diverse concept from branding. As in comparison, companies usually take a more extended period or majorly stay the same with their branding strategies; however, they continuously update \& alter their marketing strategies/campaigns to let their customer know about them. Although the sister concepts work hand in hand for the practical outcomes of both, pinning concerns arise in which of these component acts first or must initiate initially.

As mentioned above, branding is the initial stair of creating a brand's self-identity and making it an exceptional result in itself. Nonetheless, marketing, which includes Electronic \& print media promotions accompanying traditional media promotions, aids in successfully interpreting a brand's branding. 


\section{BRANDING IN THE PHARMACEUTICAL INDUSTRY}

Branding \& pharmaceutical industries are comparatively new to one another because of the nature of the pharmaceutical industry. The industry believes in lengthy R\&D before deciding on a trend to follow as medicinal drugs take a longer span to develop and then market them is a whole lot different story. Nevertheless, as this is the digitalization era \& being visible on screens, any industry or brand that does not market itself enough will not stay for a long time in the market.

The pharmaceutical industry has revolutionized its branding practices and made an impeccable result out of it. However, the industry has not changed because it does not walk by the traditional means of branding in the sense that TV \& Print media are only a partial part of its marketing activities.

The pharmaceutical industry worldwide has adopted a mobile marketing strategy to promote prescription medicines with medical or sales representatives. These agents are lying in the initial tier of a pharma company's marketing team \& ultimately becomes the face of the company in front of its customer, i.e., physicians \& pharmacists. Along with these, the digital appearance of pharma companies has helped the industry a lot to flourish

\section{BRANDING IN THE FAST-MOVING CONSUMER GOODS} (FMCGS)

FMCG industry has been under consideration for its variant nature $\&$ the type of tangible products it deals with. Since the industry's existence, relevant branding strategies discovered \& safe-to-say with time, the strategies have been updated.

Products which come to the umbrella of FMCG are the ones which require the appeal advertising of themselves. Unlike medicines that require their branding to be "Information oriented". Thus, Traditional Media (Print \& electronic Mediums) have been the aiding tool for the FMCG industry to "brand" its products.

As discussed in the above contexts, branding comes beforehand the marketing phase \& if applied to the FMCG Industry's context; then things would be as like the following:

\section{Brand Extension}

2. Flanker/Fight brand strategy

3. Line extension

4. New brand strategy

These four strategies are widely used brand strategies in the FMCG industry, followed by relevant marketing activities. FMCG industry is a well competitive \& furious industry on its own, though it is a massive investment demanded industry; however, companies are still entering the market globally. This makes the existing companies afraid of their existing brand models, and to cater the worrying concern of companies, marketers have introduced such aforementioned branding strategies to cope with the competition in the respective industry. Additionally, digitalization in social media mass or niche marketing has been the ultimate branding weapon introduced $\&$ immensely leading in the FMCG industry.

\section{RESEARCH OBJECTIVE}

The following research's prior portion thoroughly dissected that "Branding" still exists in the pharmaceutical Industry. Furthermore, the main objectives of the study are extended in the following:

- Analyze the branding strategies of the Pharmaceutical Industry in comparison to the FMCG industry,

- Relate the comparative findings with the ultimate needs of the modern world.

The intended research objectives will help draw out recommendations regarding comparing the pharmaceutical \& FMCG industry's branding strategies and how it will provide a new dimension to research and practice for the marketers.

\section{RESEARCH METHODOLOGY}

The envisioned research objectives will be obtained based on past literature. Peer-reviewed research articles \& papers from the tenure of 2010 till data will be exclusively indulged in following research's objective.

\section{LITERATURE REVIEW}

The following article's literature review is diverged to develop and understand the comparison between the pharmaceutical industry's branding strategies \& the FMCG industry, respectively. However, one-by-one, the relevant peer-reviewed articles will be re-reviewed in the upcoming portion of literature to fully construct a two-way dimensional study area and draw conclusions out of it fittingly.

\section{A. Branding with Product Names}

Branding with names is a quite popular branding strategy used in almost every other industry. For the particular discourse, the following literature will provide evidence from the respective industries of Pharmaceutical \& FMCG to draw similarity or dissimilarity partiality in the conceptualization \& branding implementation.

A study by Wineinger, Zhang, and Topol [3] proves that how branding with names such as indulging medicinal drugs with molecules names creates a brand image in itself. The study was focused on how prices trend fluctuates among specific brand names. The research was conducted by using 49 top-selling branded medicines in the United States. The price trends of selected drugs were selected from 20122017. Results were summarized as 132 medicines of the 45 selected branded medicines with an uplift prescription rate amongst the branded medicines that do not apply branding with their business model names.

Similarly, the FMCG industry is full of 'what attracts in the first glance is what the customer will buy' type. Why is why; a study by Laforet [4] is considered to understand better how to name branding influence consumer of the FMCG industry and their purchase decisions. The researchers aimed to achieve corporate, dual \& product brand names, which influence consumers' purchase decisions. Sixteen randomly selected brand names belonging from three different price ranges were selected for 
observations \& face-to-face interviews were conducted. Multiple linear regression techniques analyzed collected data. Corporate brand names were found to be the most influential factor that shaped the consumer's purchase decision.

In comparison to both of the studies incurred above, not only evidence exists about the prevalence \& implementation of name branding in FMCG \& pharmaceutical industries. What benefits this branding strategy can potentially return on the company; it is also discussed above to increase prescriptions \& sales.

\section{B. Branding with Free Samples, Reminders \& Gifts}

Creating a brand image in front of the potential customer is something every industry and company strive for. Businesses pay millions in developing effective branding strategies for their brands, which is justifiable in the present era. Market dynamics are thriving with a 360-degree angle daily regarding marketing approaches, customer preferences, and competition in the market from every little branding element.

Henceforward, Rafique, Sarwar, Rashid, and Sheerin [5] conducted a cross-sectional study. The researchers developed the objective of examining the phenomena if a doctor's prescription is affected by dispensing free samples. Questionnaires, containing open \& close-ended questions, were filled by doctors in the hospital regarding their views $\&$ preferences. The questionnaire was divided amongst the selection of testers between the acid-peptic diseases \& rheumatoid arthritis. Findings were concluded with the statistical analysis of Chi-tests. Doctors preferred the free samples of acid peptic diseases more than the other tester and displayed hints of prescribing it to their patients.

This explains how knowledgeable the pharmaceutical industry consumers are because they thoroughly dissect every little element of testers provided to them before dispensing it to their patients.

Conversely, this further points towards the rationale of whether physicians even consider free samples $\&$ gifts as an ethical practice.

Khazzaka [6] studied pharmaceutical marketing tactics as gifts \& samples on physicians' prescribing behavior in Lebanon's developing country. The researcher aimed at targeting two concepts throughout the study, 1) Whether prescription behavior of middle eastern country Lebanon's physicians are affected by the pharmaceutical marketing activities, and 2)Whether Lebanese physicians even consider accepting free samples \& gifts as an ethical practice amalgamating their profession's vital description (Dispensing of medicines). The study, however, was prosperous about the decision criteria when concluding its outcomes.

Nonetheless, the outcomes were obtained by conducting a cross-sectional study using Whatsapp; generated data was cleaned through Cronbach Alpha's reliability test. It was found out that the prescribing behavior of Lebanese physicians is correlated to the pharmaceutical marketing tool. As physicians mostly use the dispensed free sample medicines on their patients, while gifts were comparatively impressive for physicians. Anyhow, physicians overall did not consider dispensing of free samples \& gifts as an ethical practice. However, this variation in views was dissected as the variation between physicians' demographic characteristics such as age, income level $\&$ job status level as specialists \& general physicians.

The study by Khazzaka [6] provided a wholesome view of how much significant pharmaceutical marketing activities are in Lebanon's middle-eastern developing country. Moreover, it gave the idea of how views regarding free samples \& gifts diverse ranging from physicians to physicians.

Furthermore, Woinhareg [7] examined Ethiopian doctors' prescription behavior. The researcher initiated intended research with thoughts that physicians' prescription behavior does get affected by several factors; hence, the study straightforwardly conveyed the impact of pharmaceutical marketing activities such as sponsorships \& other promotional referencing.

Two hospitals, namely, the Tikur Anbessa Specialized Hospital and Addis Hiwot General Hospital, were chosen to be the geographic boundary for the very research \&, as such, no specific sampling technique regarding the population of respondents (doctors) was used. The reason for this was found out to be the hint of deliberate behavior showoff by the doctors if informed before the sampling. The research objectives were focused on the medical representatives/promoters who exhibited promotional tools to the physicians and their relatable outcomes. Anyhow, 174 physicians participated in the study \& filled a selfadministered semi-structured questionnaire. Findings were developed \& concluded into two sections based on the nature of responses by the respondents as:

1) Physicians majorly predicted that there is no significant dissimilarity in between the quality, characteristics \& functionality of both generic medicinal drugs \& branded drugs (promoted by the medical representatives); however, this was a bonus outcome for the researcher as price comparability was not the intended objectivity of this research. Nonetheless, the second-dimensional outcome fulfilled the research objective.

2) Sponsorship techniques have little or no influence on the Ethiopian doctors working in the case study hospitals.

Nevertheless, the researcher commented that pharmaceutical advertisements were found to have a relatively higher impact on doctors' prescription behavior.

The study mentioned above gave a focal dimensional brand strategy that can be fully \& more thoroughly implemented in the Pharmaceutical industry as advertisements are found to be more effective in enhanced prescription behavior of branded medicinal drugs.

Similarly, Mohammad \& Salah [8] researched the means of analyzing the pharmaceutical marketing influences on the rational prescription \& health professional manners of physicians \& pharmacists in Sudan. The researchers aimed for their study because of the vitality to measure the healthcare industry \& pharmaceutical industry's sensitive relationship.

Researchers carried out a cross-sectional survey for seven months, almost starting from 2013 September till March of 2014 in Sudan called Khartoum. Randomly, questionnaires were filled by 200 healthcare works (including physicians, doctors \& pharmacists). Findings concluded that $53.8 \%$ of 
physicians agreed that pharmaceutical promotional tools influence their prescription behaviors, and $44.6 \%$ of pharmacists agreed on the same matter. Henceforward, the research's remaining portion was answered by the physicians \& pharmacists both as they find frequent visits by the medical representatives and gifts \& samples are important influencing trigger for their rational prescription.

The researchers concluded the study by providing hints where the respondents underestimated their professional ethics about pharmaceutical promotional tools.

Another study conducted in the Middle Eastern country, Sudan, confirmed the prevalence of pharmaceutical marketing tools for influencing physicians prescribing behavior. Ahmad [9] published a relevant research article in the Sudan Journal of Rational Use of Medicine, where the researcher carried out a concrete conclusion by linking the history of Pharmaceutical marketing in Sudan.

The researcher narrated that Branded medicinal drugs in Sudan have marketed hand in hand with the generic medicinal drugs, which clears out the doubt against the branded drugs' quality \& functionality. Free samples, gifts, $\&$ other benefices are the highlighting portion where pharmaceutical marketers are winning, and this is becoming more prominent with the participation of junior physicians. The article was concluded as junior physicians show irrelevant interest in the promotional tools offered by the medical representatives \& which causes unintentionally or intentionally attraction towards the promoted medicine, resulting in enhanced prescribing behavior.

Peer-reviewed research $\&$ articles from around the world provided concrete evidence of respective countries' physicians \& pharmacists dispensing rational behaviors being affected by the free samples, gifts \& other promotional tools.

\section{Branding through Events, Workshops \& Conferences}

Pharmaceutical industry is one of those industries which are famous for their PRs \& persuasive nature. This could be justified by the nature of the respective industry, as medicinal drugs need to be informed well. Apart from their visible marketing, which is why the vitality of events, workshops \& conferences needs to be discussed in the pharmaceutical Industry.

Roshni, and Narendranathan [10], conducted a study in India to understand which of the marketing techniques of pharma companies affect the prescribing behaviors of doctors. The researchers were, anyhow, considering all of the pharma companies' promotional tools; however, their main emphasis was on the conferences \& events hosted by pharma companies. A self-administered questionnaire was filled by 50 Indian doctors \& 53 medical representatives to know their take on the respective research $\&$ its objectivity. The collected data was then analyzed onto 36 pre-decided variables ranging from quality of the medicinal drug being promoted at the conference to the medicinal drug's price being promoted through the branded workshop, which is hosted/managed by the medical representatives.

Results were very vast, as data analysis was majorly distributed upon the staircases of Likert scale \& reliability results and so on. The medicinal drug being promoted at the branded conference was the most useful parameter that hit the Indian doctors prescribing behaviors. However, medical representatives were entirely in support of these branded conferences held by pharma companies' cause these events half the burden of MRs as they do not necessarily have to go to every single doctor then for individual branding of the drug.

The research mentioned above was helpful as it provided a new opinion regarding the views of MRs towards branded conferences along with the hints provided by health practitioners as a form of efficient performance exhibited by the branded conferences. Anyhow, the views of pharma companies who host these medicinal conferences, workshops \& conferences still lacks to study, thus provides a new dimension to research for researchers.

On the other hand, a different study conducted in 2013 by Lavorini et al. [11] provided somewhat similar findings but through a completely different face. As the researchers aimed at analyzing how generic asthma \& COPD medicines are taking over branded inhaled medicines. The researchers indicated significant factors that prevail in using generic medicines more than branded medicines through the medicinal workshops.

On review, the statistics from Europe alone, the researchers narrated that even though branded medicines are majorly promoted in events, conferences \& workshops by the respective pharma companies; the disturbing factor of customers (patients themselves) switching to generic medicines is visible. Here the demographic context of patients (Asthma \& COPD), mattered a lot as the patients self-analyze themselves \& switch to generic inhaled drugs because 1) They are reliable as the particular generic drug has cured them or their acquaintances many times, and 2) Misconception regarding the branded medicines that they carry a high percentage of side-effects in them.

Nonetheless, the researchers cleared out the two significant themes of reviews obtained from European patients \& highlighted the need for more awareness camps by pharma companies, even before launching their particular branded drug.

Branding through events, conferences, and workshops is an influential promotional tool used by the pharmaceutical industry to persuade their customers (Physicians \& Pharmacists, physicians mostly). With that being said, Lavorini [11] recommended the lack of awareness in the customers regarding the branded medicinal drug as some ratio of them attend such events, medical conferences \& workshops for the sake of free samples, gifts \& other sponsorships.

The above-given literature review is wholly related to the pharmaceutical industry \& relevancy is provided to the respective industry. However, the upcoming literature will present a comparison view of both the industries; Pharmaceutical \& FMCG

\section{Branding, Co-branding \& Brand Extension}

It was only the old-time; when "branding \& marketing" were confined to specific industries \& mainly to only FMCG industry; but as the market is updated, consumers are more knowledgeable and fore mostly competition is rising day-by-day in every industry; Brand managers have evolved accordingly. 
The under-consideration industries of pharmaceutical \& FMCG are both full of competition to their necks in their respective markets. Hence, a comparative literature review will be entitled in the upcoming context to justify whether the branding exists in both of the industries in the equal ratio, and if it does then, to what extent does co-branding \& Brand extension is present in the pharmaceutical industry in comparison to the FMCG industry.

\section{Branding}

Kishore \& Rao [12] mentioned the importance of branding in the pharmaceutical industry \& presented a detailed view of branding's existence in the respective industry. The researchers mainly focused on the competitive pharmaceutical market of India \& drawn conclusions \& recommendations for the same. Primary data collection was done by interacting with the product managers/brand managers and marketing managers of various pharma companies. However, the secondary portion of data collection was referred from credible online sources.

Upon data analysis, it was found out that brand managers especially put effort \& extreme amounts of R\&D in deciding the name of their medicinal drug brand. Brand managers exclusively pointed towards two factors before deciding on a brand name; and how these referred two factors contribute to their drug branding. Brand communication \& brand image are the two elements/factors that majorly affect selecting the foremost part of a drug branding: its name. Naming brands based on which chemicals are they made up of, their dosage and every relevant detail that gets narrated on the first glance by the customer (physician \& pharmacists) are behind the selection criteria of a brand's name.

Compared to the research mentioned above, a study by Tariq et al. [13] perfectly fits the context. The researchers conducted exploratory research to determine consumers' purchase intentions of the fast-moving industry; however, consumers' purchase intention was analyzed concerning the FMCG industry's efforts in its branding. A cross-sectional study was implemented on a population of 362 Pakistani consumers, and results were drawn accordingly. Branding consists of numerous elements, and these elements are what consumers assume as product quality, Product involvement \& product knowledge.

Thereby, through the medium of this very research, branding 'element in the FMCG industry known as the product quality is found out to be the most influential variable for affected consumers' purchase intentions.

Tariq et al. [13] \& Kishore \& Rao [12] significantly researched the importance \& implementation of branding in the pharmaceutical \& FMCG industries, which amalgamates in the outcome of branding being implemented in the pharmaceutical industry in the equal comparison as in the FMCG industry.

\section{Co-branding}

Co-branding is defined to be the strategic alliance of twoor-more brands for the shared purpose of mutual benefits of both the brands. Co-branding is considered an efficient way for brands to improve their brand's operational value \&, eventually, their brand image in every Industry. The upcoming literature will be focused on the Co-branding evidence existing in the Pharmaceutical industry.
Tolochko et al. [14] examined the implementation of Cobranding in the social services field regarding the pharmaceutical industry. The researchers highlighted why the Co-branding of both the industries is effective \& what indeed is lacking in between the Co-branding. Trade-Union leadership was found to be the binding ingredient that holds the relationship mentioned above between the industries \& further, the procedure of this co-branding procedure was explained. Apart from the exchange of resources (mainly from the pharma industry to Social Services), employees from pharmaceutical industries are also transferred to social services sectors to correctly promote the exhibited relationship.

Furthermore, the bookish concept of Co-branding was missing out on a big-time in the relationship of both the industries; however, conceptually, both the sectors are performing pretty well.

On the other hand, the FMCG industry is not lacking in Co-branding implementation, and the following study will provide evidence of that.

Co-branding is witnessed in the FMCG industry for a long time. The real question is, how does Co-branding work in the industry of FMCG? Knape, Ellen, and Rodestedt [15] examined the existing strategies that successfully implement Co-branding in the FMCG industry.

The researchers divided the dimensional academic nature of this research into the degree of perceptual fit \& strength of brand-specific association transfer. FIT (New product brand-fit) \& FAT (Full association transfer) were found to be the strategies that ease down the process of Co-branding, both for the industry $\&$ the consumer.

The above-given literature contribution can confirm that the pharmaceutical industry's Co-branding is comparable to the Consumer Goods Industry's Co-branding.

\section{Brand Extension}

Amin, Tahir, and Kesselheim [16] identified a case secondary patenting of branded medicines; and highlighted how the transformation of customers of preferences in generic medicinal drugs to branded drugs. The research did examine the exploratory variant patents that exploit in aiding the market captivity for the brand, extension its medicinal drugs nature.

The research can be considered evidence where the pharmaceutical industry is notably transforming itself according to the branding strategy of brand extension. However, other literature will compare and present the brand extension evidence in the consumer goods industry.

Mann, and Kohli [17], identified the brand extension announcement in FMCG companies' impact on the shareholder's wealth in India. Additionally, the researchers aimed to assess the analysis mentioned above outcomes concerning the pharma versus FMCG acquisitions. Plus, the impact of pharma versus FMCG acquisitions was dissected by cross-border buyouts, making the following study a rich piece of work. For the announcement of brand extensions, standard event study methodology was implied for the study's particular discourse. Nonetheless, the comparative extensions of both the industries across borders were analyzed \& computed, respectively. Results were narrated as the announcement of brand extensions in India's FMCG industry positively impacted the shareholder's wealth as 
they instantly gained more returns by linking up to a new brand (in extension). Further, the study gave hints in favor of implying brand extensions to increase shareholder wealth in the FMCG industry. These studies provided an in-depth analysis of Branding, Co-branding \& Brand extension in the pharmaceutical industry compared to the Consumer goods industry.

\section{E. Corporate Branding Strategy}

Dinnie [18] defines "corporate branding" as a much broader aspect than branding's products and services. It is typically the brand name promotion as a whole, and not of any; it is any offered product or services. However, the products \& services of a brand do aid in promoting the corporate brand name. Nonetheless, both are two different scenarios \& hence required distinguished branding strategies.

For now, the upcoming literature will be focused on the branding strategies of corporate names/images, which following would provide a comparative view in the industries of FMCG \& pharmaceutical, respectively.

Kaufmann, Ruediger, Vrontis, Czinkota, and Hadiono [19], conducted a study to analyze how communication regarding environmental changes to stakeholders helps build a better corporate brand image in the FMCG industry. A triangulation survey approach was implemented to fulfill the research and surveys' intended objective, questionnaire, interviews \& case study technique implied to the particular discourse.

Using experimental \& explanatory research methods, the significant element of Behavioral Branding was identified by the data analysis. This indicated that CSR is an "in-thing" and apart from consumer goods branding, the brand wholly solely images behind it gets promoted by it efficiently.

In regard to the research mentioned above, pharmaceutical industry is full of studies that evident in how much corporate branding prevails in the respective industry $\&$ the variables that contribute to building the Pharma Industry's corporate image.

Hyojin and Ball [20] presented a study on the rationale existing between the customers of medicines and pharmaceutical industry itself; regarding the respective industry's corporate brand image. The researchers indicated that as far as the pharmaceutical industry is concerned globally, relevant customers do not relatively concern about the branding \& marketing of drugs; however, this is a severe issue. Since pharmaceutical industry itself is a growing and competitive industry that carries a significant risk of forgery products, corporate branding is something that brand managers of the pharmaceutical industry must take care of.

Hyojin and Ball [20] researched the need for corporate branding in the pharmaceutical industry as the research did show evidence about why the industry is capable of doing so.

Carrying the outcomes of the research as mentioned earlier in the domain of pharmaceuticals, a study by Chen et al. [21] contributes much to the pharmaceutical industry's uses and implication of Taiwan's corporate reputation. The study was conducted to define the uses of the Taiwanese Pharmaceutical Industry's right corporate image that the industry itself can enjoy and eventually provide benefits in satisfying product (medicines) quality to the end-consumer.

For the very purpose of the following research, in-depth interviews were conducted with the top managers of Taiwanese pharmaceutical companies \& results were drawn from the amalgamated views of peer-reviewed articles, growth statistics of pharma companies who have an excellent corporate image $\&$ the primary data collection. It was found out that Taiwanese pharmaceutical companies who have the right corporate brand image enjoy three benefits compared to their competitors who lack this dimension. 1) Hedonic value, 2) Cost value, and 3) Expressive value.

The study evidenced the findings in two sections:

1. Pharmaceutical Industry can get numerous benefits from having a well-stabled corporate brand image,

2. Consumers of healthcare needs to be aware of the relative drug for the disease/condition, as the pharmaceutical industry is full of "generic brands".

Lastly, Zaman, Arshad, and Shahzad [22] proposed a study in the FMCG sector of Pakistan to analyze how FMCG companies can increase their customer's loyalty by having a well reputed corporate brand image. Two hundred respondents were chosen to employ random \& convenient sampling.

Upon conducting informal interviews from respondents, the obtained data were dissected with the statistical analysis tool's help, i.e., multiple regression \& correlation coefficient. Regression analysis was able to find $70 \%$ relevance of customer's loyalty with the well-reputed corporate Brand FMCG Company. However, the remaining population chose Brand associations as a variable factor, influencing them to show loyalty to an FMCG company.

Thus, as mentioned earlier, the study enhanced the corporate brand image strategies to influence customer loyalty \& eventually increase the market captivity for the Brand.

\section{F. Branding through Mass Media}

Mass media is quite a broad marketing medium in itself, ranging from television, radio, internet to print media where communication strategy comprises to cover a larger number of audiences. As discussed in the article before, the FMCG industry exclusively demands visible promotions to appeal to the customer. Thereby, the upcoming literature will be majorly focused on mass media branding in the FMCG industry only.

Hameed, Soomro, Butt, and Shakoor [23] conducted a study in the Pakistani FMCG industry to examine how mass media helps the respective industry flourish. The researchers initiated the study by throwing light on TV's importance in the present decade $\&$ the foreseeable future. A questionnaire containing semi-structured questions of TV Marketing; and 320 university students were selected for data collection. Upon data dissection, it was found that $86 \%$ of respondents were all together in support of FMCG companies who would use TV marketing to promote their brands, products \& services as a whole. This literature provided a brief picture of how the FMCG industry has been mass-marketed worldwide and how much it is imperatively affecting the FMCG industry \& consumers' relationship.

The pharmaceutical industry broadly uses print media to 
promote their medicinal products. Newspaper or magazines ads of prescription medicines that promote medicines directly to the patients are unethical and prohibited by countries' drug regulatory authorities. Pharmaceutical sales team promote medicines through printed brochures to doctors, but they are not supposed to contact end users (patients) directly. Television, radio, or internet marketing is prohibited by countries' drug regulatory authorities due to abuse use of medicines or self-medication, which may turn to quite dangerous for patients even life threatening.

\section{G. Branding in Digital World}

Digital world is a broad and in-trend marketing medium, and as the current economic situation, and it will not be going anywhere soon. Hence, the condition of digital branding is very vital to understand in the industries of FMCG \& pharm. However, the following literature will help create a comparison of success between the two industries (if any).

Heba, Elwy, and Eldallal [24] presented a study in the Egyptian fast-moving consumer goods industry to understand how brand-created social media accounts, particularly Facebook, potential target customers, and different molds decision into buying the promoted product. Four hundred consumers were selected based on quota sampling \& results were analyzed with the Structural Equation Model (SEM), and results were drawn after then.

Perceived quality and brand associations were found out to be the two variables that affect consumers to click on the social media page of FMCG Company particularly and then influencing them enough to purchase the product being promoted.

Similarly, Bednarz \& Orelly [25] researched the Bangladeshi consumer goods market to understand how social media communication helps both the manufacturers $\&$ consumers connect with each other. One hundred respondents were selected to be a part of the research \& face-to-face interviews were conducted to gather data. Results were concluded as two social media apps YouTube $\&$ Facebook are the most influential for consumers who buy the promoted product as Facebook helps the consumers get information about the product \& YouTube provides a virtual review of the product to the potential consumer.

Apart from the FMCG industry, the pharmaceutical industry is also providing rich literature regarding digital branding practices in the respective industry.

Mishra and Sanghvi [26] conducted a study on the promotional strategies implemented by pharmaceutical organizations through social media. The study was based upon the virtual presence of pharmaceutical companies \& how it is rightfully affecting their potential customers. The researchers identified blog posts as the most convenient \& useful social media tool to disseminate information regarding the medicinal drug to end $\&$ potential consumers.

Likewise, a cross-sectional study was conducted in Saudi Arabia by Said et al. [27] that combined the direct-to-digital marketing techniques prevalence \& effectiveness. Face-toface interactions filled with standardized questionnaires and data analysis was then conducted. After secondary data analysis consideration, results were concluded as well. Consumers preferred digital media to be a useful source of information dissemination regarding medicinal drugs. In particular, chat boxes \& health blogs were quoted by the majority of respondents gathered through random sampling.

As mentioned earlier, the literature has drawn a clear circle around the prevalence of digital branding in FMCG \& Pharmaceutical both.

\section{H. Examples of Successful Branding Strategies: Pharmaceuticals vs. FMCG}

The pharmaceuticals \& FMCG industries have proved themselves numerous times from their remarkable performances and customer satisfaction levels. However, the following literature will discuss how pharmaceuticals \& FMCG industries are successfully implementing their branding strategies and taking benefits from it.

Chao et al. [28] presented a case study research on one of the Pharmaceutical Industry giants, Pfizer. The researchers examined the successful case of Pfizer, when Pfizer managed the patent expiry of Lipitor (a brand uses to manage high cholesterol levels). The study mainly focuses on the challenges faced $\&$ managed by Pfizer to manage the pharmaceutical patent expiry matter \& how this case further aided Pfizer to build a strong brand out of Lipitor. By applying a case study approach, researchers were able to find out results that were diverted into two phases: Prepatent expiry and Post-patent expiry.

Researchers described Pfizer's pre-patent expiry phase as legal delay, DTC (direct-to-consumer) marketing, me-too drug $\mathrm{R} \& \mathrm{D}, \&$ most obvious pricing strategy for tackling competition. However, the post-patent expiry tenure was dealt with as a rebate strategy, change to OTC distribution, continual changes in marketing strategies, and authorized generics.

The study was fruitful for both generic drug companies \& brands as 'managing patent cliff' is one of the toughest challenges for an industry as pharmaceuticals. Along with the internal branding of Lipitor, branding (patent expiry) of the brand itself was very much praised in the global market. Hence, this research provides a vital view of learning from challenges \& efficiently handling them, an example for all firms out there.

This marks a remarkable branding case in the history of the pharmaceutical industry by far; however, in order to draw a conclusion, a successful branding case related to the FMCG industry is following.

Gupta [29] presented a case study research in India on the consumer goods company of Patanjali, Ayurveda Limited, which deals in juices, food, Ayurveda herbs \& cosmetics, etc. The researcher aimed the study towards an alarming market situation of disruption. As the study was explanatory and for the secondary means of data collection, past achievements, struggles \& challenges the company faced were analyzed. Outcomes were concluded based on two things: The extent to which Patanjali Ayurveda has transformed its branding \& marketing strategies and how Patanjali has distinguished itself from its giant competitors existing in the Indian FMCG market, i.e., Unilever, etc.

Although Patanjali is a new enterprise compared to its competitors, the firm has transformed its branding strategies and choose a brand image as its weapon. The firm created a USP in its product and tactically used "Ayurveda". This 
explains how smartly the enterprise deep-rooted it is branding in the minds of its potential customers.

Both of the above presented successful branding case studies provided a diversified view of the objectivity of the literature review. Ranging from internal branding focused on the patent expiry matters in Pfizer's giant enterprise to external branding used to survive in India's disruptive market by Patanjali Ayurveda Limited. Numerous learning outcomes can be obtained for the knowledge from these successful branding studies.

The thorough review of past studies in the former content is supportive to demonstrate the following research's objectivity.

\section{CONCLUSION}

Living in the midst of a global pandemic, health practitioners, researchers, and every other drug company strive to find the cure that will help humankind get rid of this disastrous pandemic. Only this is the time to emphasize the vitality of medicinal drugs \& the healthcare industry as a whole enough for their commendable services. Nevertheless, the real question is, Are We? Are we even recognizing what medicinal drugs (be it a branded or a generic drug) play in the world presently or will play in the upcoming future? The answer to this question can easily be aided by the thorough findings of this review article.

The research not only focuses on the branding of the pharmaceutical industry \& efficacy. It is also providing a customized corpus analysis on the pharmaceutical industry's branding efforts by comparing it to the ever-growing industry of consumer goods.

Branding strategies ranging from name of brand naming to branding in digital world; all have been methodically reviewed for this article's specific discourse. The findings are hypothetically filling the intended objectives of this research as both the industries share some similarities in branding strategies, but their implementation is strategically different.

However, lacking in the analysis phase of such branding strategies as marketing strategy of direct to end users (patients) in pharmaceutical is a complete abrupt as viewer (consumers) perception is creating a hurdle in the correct decoding of the message being conveyed by the brand.

Nonetheless, the pressure lies upon the fact in which way does this specific research's findings fulfill the modern world needs. In the pharmaceutical industry's global market, like any other industry, competition is growing way too fast. To survive in the pharmaceutical market, companies must sell the medicines in the best ethical way possible, and there is why the following review article will aid in. Naming of brands, corporate branding, free medicines sampling to physicians for patients as trials, brand Extension, Cobranding, \& digital branding are among the many branding strategies majorly in the pharmaceutical industry, which provides impeccable benefit to the industry and consumer loyalty. Nature and way of processing things in the pharmaceutical industry are much more rigid \& strict than in FMCG. Nevertheless, again, acceptations can be made; only if brand managers of the pharmaceutical companies make branding of companies a priority.

\section{RECOMMENDATIONS}

From the corporate perspective, the Pharmaceutical industry should consider the following recommendations to jump on the bandwagon of efficient branding fully and equal or compete the FMCG industry in branding.

- Globally, national or local pharmaceutical companies of every other countries must manufacture its drugs within its territory. Though costs \& expenses do not contribute to a pharma company's branding, the locally manufactured concept can contribute a lot to a brand's corporate \& market image.

- Create a fine balance line between investments in the R\&D of a drug and its branding budget. Both play an equal part in its sales graph, then why not treat equally enough.

- Run by the world in terms of following what is trending in branding. Keeping into consideration the sensitivity of the respective industry, but digitalization requires no explanation.

- Consumer goods industry is a time-tested industry in terms of marketing and branding, and to some-extent, pharmaceutical industry is following consumer goods industry foot prints in marketing tactics. Nonetheless, engaging in brand extensions \& mergers to aid the famous branding world of FMCG.

- Take aid from the necessity of "brand awareness" in the industry \& run branding strategies alongside it.

- Branding in the pharmaceuticals industry targets the customers which are the doctors and not the end users or consumers (patients), while FMCGs marketing and branding strategies are concentrated towards end users. Therefore, brand managers in pharmaceuticals should always chalk out their brand plan as per the physicians' or doctors need, which may be medicine sampling, product training, clinical studies, learning through workshops or patients' centered clinic reminders etc.

\section{SUMMARY}

FMCG \& pharmaceutical industries require the same amount of branding, presently, as like any other industry. However, gaps are still existing from pharmaceuticals side. The following review article presents systematic literature regarding the prevalence \& implementation of branding strategies such as branding with names, co-branding, brand extension, branding with free samples \& sponsorships and digital marketing in pharmaceutical \& FMCGs. This is followed by comparative literature from the consumer goods industry as well.

The paper concludes that relatives' findings from the literature to satisfy the modern world needs majorly. However, specific recommendations have also been presented for the pharmaceutical industry to equal or contest the "branding race" from FMCG and along within the industry as well. 


\section{REFERENCES}

[1] The pharma letter (2001), the growing importance of branding, as pharma reaches crossroads (The pharma letter) (TPL). Available from (as seen on Oct. 03, 2020). https://www.thepharmaletter.com/article/the-growing-importance-ofbranding-as-pharma-reaches-crossroads.

[2] Ladha, Zahra. "The significance of branding in the pharmaceutical industry", Masters diss. Faculty of Business Administration-Simon Fraser University, 2005.

[3] Wineinger, Nathan E., Yunyue Zhang, and Eric J. Topol. "Trends in prices of popular brand-name prescription drugs in the United States.' JAMA network open 2, no. 5 (2019): e194791-e194791.

[4] Laforet, Sylvie. "Brand names on packaging and their impact on purchase preference." Journal of Consumer Behaviour 10, no. 1 (2011): 18-30.

[5] Rafique, Samina, Waseem Sarwar, Asima Rashid, and Fatima Sheerin. "Influence of free drug samples on prescribing by physicians: A cross sectional survey." J Pak Med Assoc 67, no. 3 (2017): 465-467.

[6] Khazzaka, Micheline. "Pharmaceutical marketing strategies' influence on physicians' prescribing pattern in Lebanon: ethics, gifts, and samples." BMC health services research 19, no. 1 (2019): 80.

[7] Yemiaamrew, Woinhareg "the impact of pharmaceutical promotion on physician's perception of new brand medicines: the case of Tikura Anbessa specialized hospital and Addis Hiwot general hospital". PhD diss., St. Mary's University, 2018.

[8] Mohammed, Ryan, and Salah Ibrahim Kheder. "The impact of pharmaceutical promotion on rational prescribing and drug use in Sudan.” Sudan Medical Monitor 12, no. 1 (2017): 19.

[9] Ahmad, Kamal Addin M. "Current modes of pharmaceutical promotion in Sudan; trading and gifts are dominating." Pharmaceutical Promotion. (2020).

[10] Narendran, Roshni, and M. Narendranathan. "Influence of pharmaceutical marketing on prescription practices of physicians." The Journal of the Indian Medical Association, (2013) 111 (1), 47-50.

[11] Lavorini, Federico, Vincent Ninane, John Haughney, Leif Bjermer, Mathieu Molimard, and Richard PN Dekhuijzen. "Switching from branded to generic inhaled medications: potential impact on asthma and COPD." (2013): 1597-1602.

[12] Kishore Babu, B., and Narasimha Rao. "Pharmaceutical Branding Strategies and Communication." International Journal of Pure and Applied Mathematics 118, no. 18 (2018): 1209-1220.

[13] Tariq, Muhammad Irfan, Muhammad Rafay Nawaz, Muhammad Musarrat Nawaz, and Hashim Awais Butt. "Customer perceptions about branding and purchase intention: A study of FMCG in an emerging market." Journal of Basic and Applied Scientific Research 3, no. 2 (2013): 340-347.

[14] Tolochko, V. M., M. V. Zarichkova, and T. F. Musica. "The analysis of applicability co-branding in the field of social protection specialists in pharmacy." Social Pharmacy in Health Care 1, no. 1 (2015): 58-64.

[15] Knape, Ellen, and Petter Rodestedt. "Co-branding in the FMCG sector: Investigating the relation between brand association transfer and perceptual fit in co-branding." Master thesis, University of Gothenburg. No. 2013:70

[16] Amin, Tahir, and Aaron S. Kesselheim. "Secondary patenting of branded pharmaceuticals: a case study of how patents on two HIV drugs could be extended for decades." Health Affairs 31, no. 10 (2012): 2286-2294.

[17] Mann, Bikram Jit Singh, and Reena Kohli. "Do brand acquisitions create wealth for acquiring company shareholders? Evidence from India.” Journal of Product \& Brand Management (2012).

[18] Dinnie, Keith. "Taking brand initiative: how companies can align strategy, culture, and identity through corporate branding." Journal of brand management (2009): 496-498.

[19] Kaufmann, Hans Ruediger, Demetris Vrontis, Michael Czinkota, and Alvin Hadiono. "Corporate branding and transformational leadership in turbulent times." Journal of Product \& Brand Management (2012): 21(3), 192-204.

[20] Kim, Hyojin, and Jennifer Ball. "Multiple levels of influence in pharmaceutical branding: an examination of industry trust, corporate credibility, and brand credibility." In American Academy of Advertising. Conference. Proceedings (Online), p. 149. American Academy of Advertising, 2013

[21] Chen, Chen-Chu Matilda, Bang Nguyen, and T. C. Melewar. "An investigation of the uses of corporate reputation: A managerial perspective in the Taiwanese pharmaceutical industry." Qualitative Market Research: An International Journal 19, no. 3 (2016): 357-376.
[22] Zaman, Khansa, Asma Arshad, and Aqeel Shahzad. "Customer loyalty in FMCG Sector of Pakistan." Information Management and Business Review 4, no. 1 (2012): 41-48.

[23] Hameed, Dr, Yasir Ali Soomro, Atif Shahab Butt, and Rehan Shakoor. "Significance of Internet Marketing in Promoting Consumer Goods in Subcontinent." International Journal of Humanities and Social Science 2, no. 13 (2012): 213-217

[24] Sadek, Heba, Sarah Elwy, and Mohamed Eldallal. "The impact of social media brand communication on consumer-based brand equity dimensions through Facebook in fast moving consumer goods: The case of Egypt." Journal of Business and Retail Management Research 12, no. 2 (2018)

[25] Bednarz, Joanna, and Patricia Orelly. "The importance of socia media on the FMCG market in Bangladesh." International Journal of Management and Economics 56, no. 3 (2020): 230-242.

[26] Mishra, Rajeev, and Deepak Sanghvi. "Promotional Strategies of Pharmaceutical Organizations through Online and Social Media." A journal of composition theory, Vol.13, (1) Jan. 2020.

[27] Said, Younes Ben, Nicola Luigi Bragazzi, and Natalia Valeryevna Pyatigorskaya. "Prevalence and Perceived Effectiveness of Pharmaceutical Digital Marketing among Community Pharmacies in Saudi Arabia: A Cross-Sectional Questionnaire-Based Survey.' Pharmacy 8, no. 1 (2020): 9.

[28] Chao, Chon Kit, Hao Hu, Liming Zhang, and Jihong Wu. "Managing the challenges of pharmaceutical patent expiry: a case study of Lipitor." Journal of Science and Technology Policy Management (2016).

[29] Gupta, Ranjita. "Disruptive marketing and brand building: A case study of Patanjali, Ayurveda Limited." Advances in Economics and Business Management (AEBM) 3, no. 2 (2016): 225-231.

[30] Arnold, Denis G., and James L. Oakley. "Pharmaceutical industry compliance with industry guiding principles for direct-to-consumer advertising." In the Customer is NOT Always Right? Marketing Orientations in a Dynamic Business World, pp. 346-346. Springer, Cham, 2017

[31] Business Research Company, (2018) - Market Research Blog-The Growing Pharmaceuticals Market: Expert Forecasts and Analysis (Blog market research). (BMR). Available from (as seen on Oct.25, 2020). https://blog.marketresearch.com/the-growing-pharmaceuticalsmarket-expert-forecasts-and-analysis

[32] Beginner -101-Branding vs. Marketing: Finding the Difference-(Out brain). (OB). Available from (as seen on Sep.02, 2020) https://www.outbrain.com/help/advertisers/branding-vs-marketing/

[33] Cheryl B, (2020) - Pharmaceutical -Annual revenue of top $10 \mathrm{big}$ pharma companies (The pharma letter) (TPL). Available from (as $\begin{array}{lll}\text { seen } & \text { on 2020). }\end{array}$ https://www.thepharmaletter.com/article/annual-revenue-of-top-10big-pharma-companies

[34] Dafny, Leemore, Christopher Ody, and Matt Schmitt. "When discounts raise costs: the effect of copay coupons on generic utilization." American Economic Journal: Economic Policy 9, no. 2 (2017): 91-123.

[35] ET brand Equity, (2016) -Digital-38\% brands allocate a third of their budget to digital marketing: Report (Brand equity Economic Times) (BEET). Available from (as seen on Oct. 12, 2020) https://brandequity.economictimes.indiatimes.com/news/digital/38 brands-allocate-a-third-of-their-budget-to-digital-marketing-report2016/53264080

[36] Gurnani S, (2016)-Opinion-The 5 elements of successful branding (Your story). (YS). Available from (as seen on Sep.19, 2020) https://yourstory.com/2016/08/five-elements-successful-branding

[37] Marion (2015)-6 min read-What is Branding (The branding Journal) (TBJ). Available from (as seen on Sep.22, 2020). https://www.thebrandingjournal.com/2015/10/what-is-brandingdefinition/

[38] Movehhad M, (2016)-Blog-Brand Strategy: The 6 key elements. (Site handshake). (SHS). Available from (as seen on Oct 11, 2020). https://site.handshake.com/blog/brand-strategy-key-elements

[39] Ofosu-Boateng, Ibrahim. "Influence of Consumer Sales Promotion on Consumers' Purchasing Behaviour of the Retailing of Consumer Goods in Tema, Ghana.” Journal of Marketing Management 8, no. 1 (2020): 24-36

[40] Salmasi, Shahrzad, Long Chiau Ming, and Tahir Mehmood Khan "Interaction and medical inducement between pharmaceutical representatives and physicians: a meta-synthesis." Journal of pharmaceutical policy and practice 9, no. 1 (2016): 37.

[41] Saswothi, Priyadarsani, Ajay Pise, Shilpa Pise, and Ligade Virendra "Perception, Attitude and Experience of Lady Medica Representatives towards Sales Profession: A Quantitative Study." Int J Cur Res Rev| Vol. 12, no. 14 (2020): 87. 
[42] Singer (2018)-6 min read-Paradigm Lost: The Value of "Branding" in the Pharmaceutical Industry. (Tincture). (T). Available from (as seen on Oct.12, 2020). https://tincture.io/paradigm-lost-the-value-ofbranding-in-the-pharmaceutical-industry.

[43] Shukla (2017)-5 min read-Lessons from FMCG branding: Branding for Technology (Part 2 of 5) by Rakesh Shukla (Medium). (M) Available from (as seen on Sep.09, 2020) https://medium.com/@ rakeshshuklatwb/lessons-from-fmcg-brandingbranding-for-technology-part-2-of-5-by-rakesh-shukla.

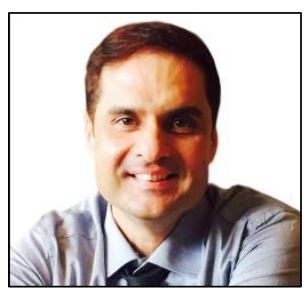

Tariq Mehmood Dar is a medical doctor. He earned his MBBS degree from Dow Medical College, Karachi University, Pakistan. He did his postgraduation in Diabetology. Dr. Tariq is a Clinical Research Certified Professional.

$\mathrm{He}$ also holds an MBA degree specialization in sales \& marketing.

He has more than 15 years of sales and marketing experience in pharmaceutical industry in Pakistan \& UAE. He worked at different position in the pharmaceuticals from medical representatives to marketing head.

Currently, he holds a position of Director Marketing \& Sales in a multinational pharmaceutical company based at UAE.

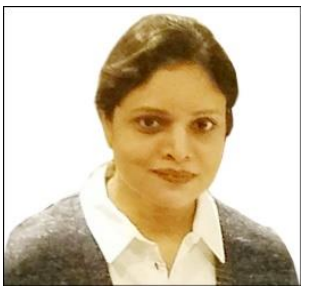

Neelofer Tariq is a professional pharmacist and seasoned marketer. She is a Doctor of Pharmacy. She earned Doctor of Pharmacy degree from Karachi University, Pakistan. She also holds an MBA degree with specialization in Pharmaceutical Marketing \& Health Management.

She is a professional sales and marketing trainer and holds more than 10 years' experience in the pharmaceutical industry of Pakistan/UAE. 